\title{
Microglia and drug-induced plasticity in reward-related neuronal circuits
}

\author{
Krisztina J. Kovács* \\ Laboratory of Molecular Neuroendocrinology, Institute of Experimental Medicine, Budapest, Hungary \\ *Correspondence: kovacs@koki.hu
}

Drugs of abuse result in complex changes in neurocircuit of reward and stress. Whilst most of these changes affect neurons, the role of additional cell types, such as glia, in the development of tolerance and related neuroplastic changes during drug taking, addiction, and withdrawal is also emerging. For instance, astrocytes, which play an essential role in glutamatergic neurotransmission, as well as in energetic and growth factor support of neurons, are significantly affected by drugs of abuse (Miguel-Hidalgo, 2009). Furthermore, the role of microglia in tailoring neuronal connectivity, transmitter metabolism, and drug-induced neuroinflammation might also be important in physiology of neurons at the addictionrelated brain circuitries.

Microglia belong to monocyte/macrophage linage and are resident cells of the innate immune system in the brain. Microglia have at least three, functionally and morphologically distinct forms (Papaleo et al., 2008; Olah et al., 2011). Under normal conditions (1) resting microglia, through their highly mobile filopodia continuously survey the brain parenchyma (Nimmerjahn et al., 2005). Microglia became activated (2) in response to various danger signals posed by neurons and/or astrocytes (Davalos et al., 2005). At this stage, microglia are recruited and have local protective effects via regulated release of cytokines and phagocytosis of cellular debris. At certain point however, microglia gain reactive phenotype (3) characterized by uncontrolled release of inflammatory mediators. These cells furiously attack neurons, became neurotoxic and extend the damage (Banati and Graeber, 1994). It is noteworthy that different insults may converge upon microglial cell population and potentiate each other to worsen the outcome of the response (Zou et al., 2011). However, like macrophages, microglial cells are functionally polarized into different phenotypic activation states, referred as classical (M1) and alternative (M2). Alternatively activated microglia express anti-inflammatory cytokines and involved in tissue protection and repair.

Activated microglia may contribute to addiction-related neuroplastic changes by several ways, such as release of proinflammatory cytokines, synaptic remodeling, neurochemical interaction with excitatory transmission and phagocytosis of newborn neurons and cellular debris.

\section{DRUG-RELATED RECEPTORS ON MICROGLIA}

Microglia posses several neurotransmitter and gliotransmitter receptors that might be involved in their activation during drug addiction. Activation of microglia by addictive drugs results in a proinflammatory dominance of the innate immune system, which is then critically synergize on the neurocircuit of reward and dependence (Coller and Hutchinson, 2012). For instance, microglia, similar to other cell of this linage (i.e., macrophages/monocytes), express opioid receptors (Bidlack, 2000; Zou et al., 2011) although their direct role in release of IL- $1 \alpha$ and $\beta$, TNF $\alpha$ remains to be established. Furthermore, it has recently been demonstrated that morphine binds to an accessory protein (MD-2) of Toll-like receptor 4 (TLR-4) and initiate release of proinflammatory cytokines from microglia and CNS endothelial cells (Wang et al., 2012). By contrast, select phytocannabinoids have anti-inflammatory (Puffenbarger et al., 2000) and neuroprotective (MartinMoreno et al., 2011) effects that are mediated by cannabinoid receptors (CB1R and/ or CB2R) which have been identified on microglia (Cabral and Marciano-Cabral, 2005; Racz et al., 2008).

Acute and chronic exposure to alcohol also results in region specific activation of glial cells (astrocytes and microglia) in doseand time-dependent manner (Crews et al.,
2011). Recent work in TLR-4 deficient mice highlighted the critical role of lipid rafts, TLR-4 and its interaction with MD-2 and CD14 accessory proteins in alcohol-induced neuroinflammation (Alfonso-Loeches et al., 2011; Coller and Hutchinson, 2012).

It is noteworthy that other abused drugs such as cocaine and methamphetamine also provoke proinflammatory immune signaling in the CNS (Lee et al., 2009), suggesting that neuroinflammation is indeed a general and critical component in the development and maintenance of drug abuse. To support this hypothesis it has been demonstrated that agents blocking microglia activation (minocycline, ibudilast) could inhibit druginduced cytokine, chemokine, and behavioral responses (Hutchinson et al., 2008, 2009; Agrawal et al., 2011; Schwarz et al., 2011). For instance, it has recently been shown that p38 signaling in the microglia in the nucleus accumbens is involved in acquisition and maintenance of morphine-induced conditioned place preference (CPP) that can be suppressed by microglia inhibitors (Zhang et al., 2012).

On the other hand, opiate antagonistbased addiction therapy inhibits innate immune gene expression (Liu et al., 2000). It should be noted, however, that neuroinflammation per se does not result in addiction, however may worsen drug effects in addicted individuals (Bruce-Keller et al., 2008).

\section{MICROGLIA AND DRUG-INDUCED MORPHOLOGICAL PLASTICITY}

It is well documented that exposure to various addictive drugs produces permanent morphological and physiological changes in dendrites, dendritic arborization, dendritic spines, and synaptic density in brain regions that are implicated in reward, decision making, and inhibitory control of behavior. For instance, stimulants such as cocaine, amphetamine, and nicotine (self-administration or repeated dosing) result in an increase of 


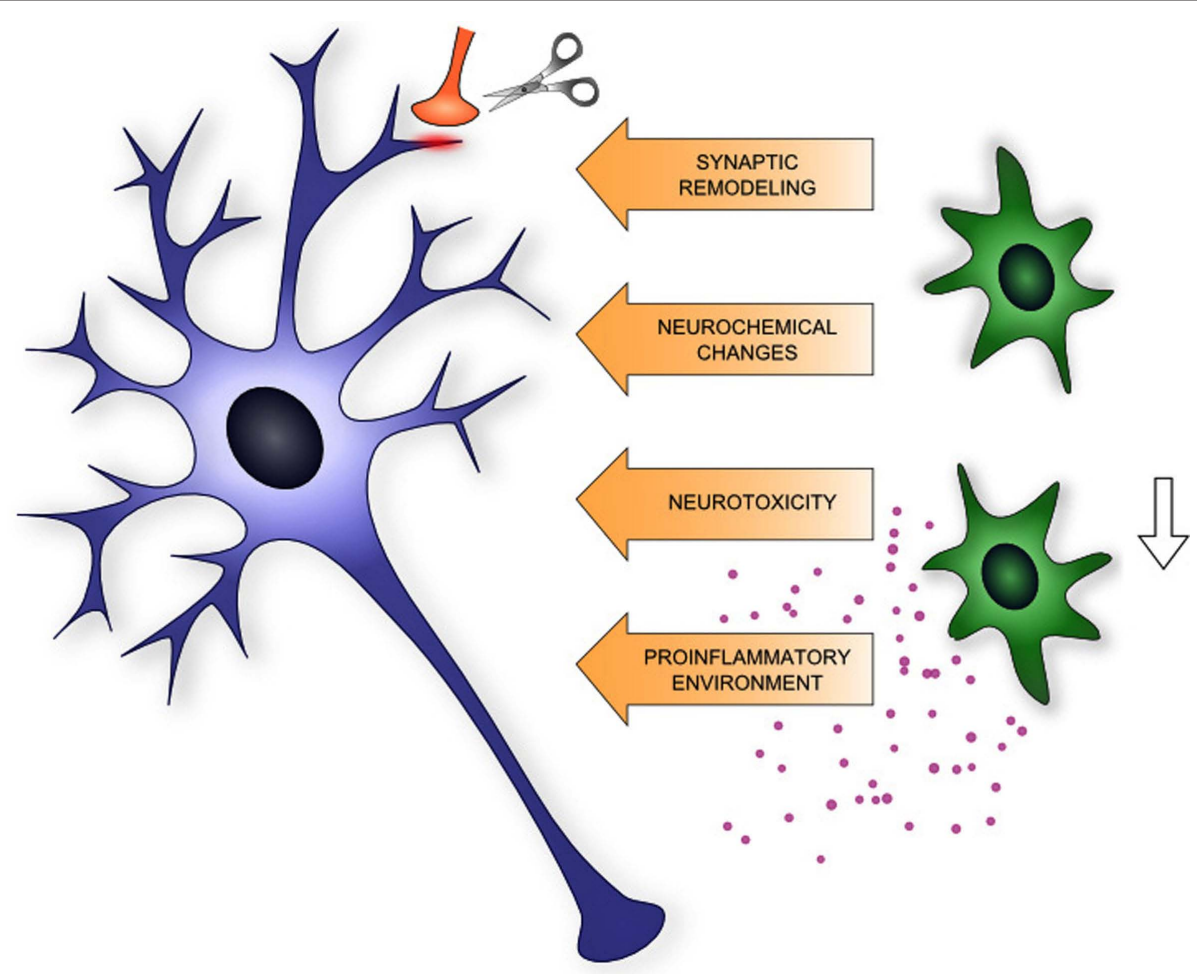

FIGURE 1 | Schematic summary of microglia (shown in green) - neuron (shown in blue) interaction relevant to neuroplasticity in addiction.

spine density on medium spiny neurons of the nucleus accumbens and on the apical dendrites of pyramidal neurons of the prefrontal cortex (Robinson and Kolb, 1999, 2004). On the other hand, depressants, such morphine, significantly reduce spine densities and dendritic branching in these areas (Robinson and Kolb, 1999). Considerable amount of information has been accumulated over the years on the cellular and molecular mechanisms that govern drug experience-induced functional and morphological plasticity (Nestler, 2004; Hyman et al., 2006). With recent emergence of microglia as effectors in neural circuit reorganization, "a new player" should be considered in drug-induced neuronal plasticity (Graeber, 2010). During development, microglia engulf, and phagocytose synapses via fractalkine-fractalkine receptor (CX3CR1) dependent manner, and play an important role in synaptic "pruning" in postnatal brain development (Paolicelli et al., 2011). It has recently been suggested that microglia may actively contribute to the experience-dependent modification or elimination of a specific subset of synapses in the adult healthy brain as well (Graeber, 2010). Indeed, microglial processes make specific contacts with synapses especially with presynaptic elements and the timing of these contacts is activity-dependent (Wake et al., 2009). Recent in vivo, two photon imaging and electron microscopy studies have revealed that microglia processes were associated with dendritic spines in experiencedependent manner, supporting the role of microglia in synaptic remodeling (Wake et al., 2009; Tremblay, 2012; Tremblay et al., 2012). Based on the significant remodeling of drugrelated brain areas and the role that microglia plays in morphological plasticity during development and in the healthy adult brain, one can hypothesize microglia significantly contribute to morphological and physiological synaptic plasticity in the addicted brain as well.

\section{MICROGLIA AND DRUG-INDUCED NEUROCHEMICAL CHANGES}

Evidences have been accumulated over the years to support the involvement of glutamatergic neurotransmission in the mechanisms of drug dependence involving the dopaminergic reward circuit. Microglia contain enzyme machinery [indoleamine 2,3 dioxygenase (IDO)] to produce quinolinic acid (QUIN). QUIN promotes glutamate release through activation of $\mathrm{N}$-methyl-D-aspartate (NMDA) receptors.
Quinolinic acid also induces oxidative stress, which in combination with glutamate release may contribute to CNS excitotoxicity. For instance in alcoholic patients ethanol may generate significant levels of, quinolinic acid, possibly even toxic levels in localized brain areas (Morgan, 1991).

\section{MICROGLIA AND DRUG-INDUCED NEURODEGENERATION}

Microglia play a pivotal role in maintaining the balance between neurogenesis and neuronal cell death in the brain via phagocytosis of apoptotic cells and necrotic debris. Neuronal stem cells and progenitors in the subgranular zone of the hippocampus give rise to newborn granular cells into the hippocampal circuit to participate learning, memory, fear, and mood regulation that are also important aspects of the addictive behavior. Under quiescent conditions microglia is ramified and seems to be neuroprotective, supporting neurogenesis through their interaction with T cells and by expressing MHCII and the neurotrophic factor insulin growth factor (IGF)-1. At this stage, microglia is very efficiently engulf apoptotic cells. However, addictive drugs decrease neurogenesis in the dentate gyrus of the hippocampus and 
in the prefrontal cortex (Eisch and Harburg, 2006) and activated microglia might be involved in this process as well. It has been hypothesized that new neurons may block memories associated with the contextual reinstatement of drug seeking or enhance extinction learning. Thus, the reduction in neurogenesis (i.e., a reduction in neuronal turnover) that is observed after self-administration of various drugs of abuse may result in a more robust and long-lasting memory of drug taking and seeking or decrease extinction learning (for review: Mandyam and Koob, 2012). In response to drug-induced microglia activation and proinflammatory environment the phagocytic potential of the microglia is further enhanced, leading to neurodegeneration.

In summary, microglia are emerging contributors of drug-induced morphological and physiological plasticity by promoting neuroinflammation through release of pro-inflammatory cytokines, by their active role in synaptic remodeling, involvement in excitotoxic neurochemical changes, and by phagocytic activity of newborn progenitors (Figure 1). Based on these facts microglia might be a potential target for the therapy of drug addiction.

\section{ACKNOWLEDGEMENT}

The work was supported by Hungarian Research Fund (OTKA) grant 76697 to Krisztina J. Kovács

\section{REFERENCES}

Agrawal, R. G., Hewetson, A., George, C. M., Syapin, P. J., and Bergeson, S.E. (2011). Minocycline reduces ethanol drinking. Brain Behav. Immun. 25(Suppl. 1), S165-S169.

Alfonso-Loeches, S., Pascual-Lucas, M., Blanco, A. M., Sanchez-Vera, I., and Guerri, C. (2011). Pivotal role of TLR4 receptors in alcohol-induced neuroinflammation and brain damage. J. Neurosci. 30, 8285-8295.

Banati, R. B., and Graeber, M. B. (1994). Surveillance, intervention and cytotoxicity: is there a protective role of microglia? Dev. Neurosci. 16, 114-127.

Bidlack, J. M. (2000). Detection and function of opioid receptors on cells from the immune system. Clin. Diagn. Lab. Immunol. 7, 719-723.

Bruce-Keller, A. J., Turchan-Cholewo, J., Smart, E. J., Geurin, T., Chauhan, A., Reid, R., Xu, R., Nath, A., Knapp, P. E., and Hauser, K. F. (2008). Morphine causes rapid increases in glial activation and neuronal injury in the striatum of inducible HIV-1 Tat transgenic mice. Glia 56, 1414-1427.

Cabral, G. A., and Marciano-Cabral, F. (2005). Cannabinoid receptors in microglia of the central nervous system: immune functional relevance. $J$. Leukoc. Biol. 78, 1192-1197.

Coller, J. K., and Hutchinson, M. R. (2012). Implications of central immune signaling caused by drugs of abuse: mechanisms, mediators and new therapeutic approaches for prediction and treatment of drug dependence. Pharmacol. Ther. 134, 219-245.

Crews, F. T.,Zou, J., and Qin, L. (2011). Induction of innate immune genes in brain create the neurobiology of addiction. Brain Behav. Immun. 25(Suppl. 1), S4-S12.

Davalos, D., Grutzendler, J., Yang, G., Kim, J. V., Zuo, Y., Jung, S., Littman, D. R., Dustin, M. L., and Gan, W. B. (2005). ATP mediates rapid microglial response to local brain injury in vivo. Nat. Neurosci. 8, 752-758.

Eisch, A. J., and Harburg, G. C. (2006). Opiates, psychostimulants, and adult hippocampal neurogenesis: insights for addiction and stem cell biology. Hippocampus 16, 271-286.

Graeber, M. B. (2010). Changing face of microglia. Science $330,783-788$.

Hutchinson, M. R., Lewis, S. S., Coats, B. D., Skyba, D. A., Crysdale, N. Y., Berkelhammer, D. L., Brzeski, A., Northcutt, A., Vietz, C. M., Judd, C. M., Maier, S. F., Watkins, L. R., and Johnson, K. W. (2009). Reduction of opioid withdrawal and potentiation of acute opioid analgesia by systemic AV411 (ibudilast). Brain Behav. Immun. 23, 240-250.

Hutchinson, M. R., Northcutt,A. L., Chao, L. W., Kearney, J. J., Zhang, Y., Berkelhammer, D. L., Loram, L.C., Rozeske, R. R., Bland,S.T., Maier,S. F., Gleeson, T.T., and Watkins, L. R. (2008). Minocycline suppresses morphine-induced respiratory depression, suppresses morphine-induced reward, and enhances systemic morphine-induced analgesia. Brain Behav. Immun. 22, 1248-1256.

Hyman, S. E., Malenka, R. C., and Nestler, E. J. (2006). Neural mechanisms of addiction: the role of rewardrelated learning and memory. Annu. Rev. Neurosci. $29,565-598$.

Lee, C. T., Lehrmann, E., Hayashi, T., Amable, R., Tsai, S. Y., Chen, J., Sanchez, J. F., Shen, J., Becker, K. G., and Freed, W. J. (2009). Gene expression profiling reveals distinct cocaine-responsive genes in human fetal CNS cell types. J. Addict. Med. 3, 218-226.

Liu, B., Du, L., and Hong, J. S. (2000). Naloxone protects rat dopaminergic neurons against inflammatory damage through inhibition of microglia activation and superoxide generation. J. Pharmacol. Exp. Ther.293,607-617.

Mandyam, C. D., and Koob, G. F. (2012). The addicted brain craves new neurons: putative role for adult-born progenitors in promoting recovery. Trends Neurosci. $35,250-260$.

Martin-Moreno, A. M., Reigada, D., Ramirez, B. G., Mechoulam, R., Innamorato, N., Cuadrado, A., and De Ceballos, M. L. (2011). Cannabidiol and other cannabinoids reduce microglial activation in vitro and in vivo: relevance to Alzheimer's disease. Mol. Pharmacol. 79, 964-973.

Miguel-Hidalgo, J. J. (2009). The role of glial cells in drug abuse. Curr. Drug Abuse Rev. 2, 72-82.

Morgan, P. F. (1991). Is quinolinic acid an endogenous excitotoxin in alcohol withdrawal? Med. Hypotheses $36,118-121$.

Nestler, E. J. (2004). Molecular mechanisms of drug addiction. Neuropharmacology 47(Suppl. 1), 24-32.

Nimmerjahn, A., Kirchhoff, F., and Helmchen, F. (2005). Resting microglial cells are highly dynamic surveillants of brain parenchyma in vivo. Science 308, 1314-1318

Olah, M., Biber, K., Vinet, J., and Boddeke, H. W. (2011). Microglia phenotype diversity. CNS Neurol. Disord. Drug Targets 10, 108-118.

Paolicelli, R. C., Bolasco, G., Pagani, F., Maggi, L., Scianni, M., Panzanelli, P., Giustetto, M., Ferreira, T. A., Guiducci, E., Dumas, L., Ragozzino, D., and
Gross, C. T. (2011). Synaptic pruning by microglia is necessary for normal brain development. Science 333, 1456-1458.

Papaleo, F., Ghozland, S., Ingallinesi, M., Roberts, A. J., Koob, G. F., and Contarino, A. (2008). Disruption of the CRF(2) receptor pathway decreases the somatic expression of opiate withdrawal. Neuropsychopharmacology 33, 2878-2887.

Puffenbarger, R.A., Boothe,A.C., and Cabral, G.A. (2000). Cannabinoids inhibit LPS-inducible cytokine mRNA expression in rat microglial cells. Glia 29, 58-69.

Racz, I., Nadal, X., Alferink, J., Banos, J. E., Rehnelt, J., Martin, M., Pintado, B., Gutierrez-Adan, A., Sanguino, E., Manzanares, J., Zimmer, A., and Maldonado, R. (2008). Crucial role of CB(2) cannabinoid receptor in the regulation of central immune responses during neuropathic pain. J. Neurosci. 28 12125-12135.

Robinson, T. E., and Kolb, B. (1999). Morphine alters the structure of neurons in the nucleus accumbens and neocortex of rats. Synapse 33, 160-162.

Robinson, T. E., and Kolb, B. (2004). Structural plasticity associated with exposure to drugs of abuse. Neuropharmacology 47(Suppl. 1), 33-46.

Schwarz, J.M., Hutchinson, M. R., and Bilbo, S. D. (2011). Early-life experience decreases drug-induced reinstatement of morphine CPP in adulthood via microglialspecific epigenetic programming of anti-inflammatory IL-10 expression. J. Neurosci. 31, 17835-17847.

Tremblay, M.E. (2012). The role of microglia at synapses in the healthy CNS: novel insights from recent imaging studies. Neuron Glia Biol. 1-10.

Tremblay, M. E., Lowery, R. L., and Majewska,A. K. (2012) Microglial interactions with synapses are modulated by visual experience. PLoS Biol. 8, e1000527. doi: 10.1371/journal.pbio.1000527

Wake, H., Moorhouse, A. J., Jinno, S., Kohsaka, S., and Nabekura, J. (2009). Resting microglia directly monitor the functional state of synapses in vivo and determine the fate of ischemic terminals. J. Neurosci. 29, 3974-3980

Wang, X., Loram, L.C., Ramos, K., De Jesus, A. J., Thomas, J., Cheng, K., Reddy, A., Somogyi, A. A., Hutchinson, M. R., Watkins, L. R., and Yin, H. (2012). Morphine activates neuroinflammation in a manner parallel to endotoxin. Proc. Natl. Acad. Sci. U.S.A. 109, 6325-6330.

Zhang, X. Q., Cui, Y., Cui, Y., Chen, Y., Na, X. D., Chen, F. Y., Wei, X. H., Li, Y.Y., Liu, X. G., and Xin, W. J. (2012). Activation of p38 signaling in the microglia in the nucleus accumbens contributes to the acquisition and maintenance of morphine-induced conditioned place preference. Brain Behav. Immun. 26, 318-325.

Zou, S., Fitting, S., Hahn, Y. K., Welch, S. P., El-Hage, N., Hauser, K. F., and Knapp, P. E. (2011). Morphine potentiates neurodegenerative effects of HIV-1 Tat through actions at mu-opioid receptor-expressing glia. Brain 134, 3616-3631.

Received: 02 May 2012; accepted: 25 May 2012; published online: 13 June 2012.

Citation: Kovács KJ (2012) Microglia and drug-induced plasticity in reward-related neuronal circuits. Front. Mol. Neurosci. 5:74. doi: 10.3389/fnmol.2012.00074

Copyright () 2012 Kovács. This is an open-access article distributed under the terms of the Creative Commons Attribution Non Commercial License, which permits noncommercial use, distribution, and reproduction in other forums, provided the original authors and source are credited. 